\title{
Zeit für Wunder
}

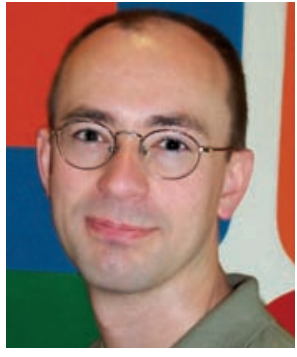

Dr. med. Dieter Schmid, Redaktionsleitung
_ Was haben Sie gedacht, als Sie Ihre neue Via medici in Händen hielten und das Titelbild betrachteten? „Das ist aber nett! Ein Blumenstrauß zur Begrüßung ..."? Oder: „Interessant! Dieses Mal geht es also um die Behandlung von Aliens“? Beides ist falsch! Unser Titelbild zeigt Bakteriophagen - Viren also, die ihr genetisches Material in Zellen einschleusen, die sie für die Produktion von Nachkommen missbrauchen. Mediziner nutzen diese virale Eigenart bei einem der modernsten Heilverfahren: der Gentherapie. Früher hat man dafür vor allem Adenoviren verwendet - heute benutzt man oft Retroviren, weil diese ihre RNA nicht nur in die Wirtszelle übertragen, sondern auch in deren Erbgut einbauen. Dadurch hält die Wirkung länger an. In unserem Artikel „Wunderwaffe Genschmuggel?“ auf $\Rightarrow$ S. 54 erklären wir Ihnen Chancen, Methoden und Risiken der Gentherapie.

__Ein Wunder ganz anderer Art wird sich in Ihrem Geldbeutel ereignen, sobald Sie Ihre erste Stelle antreten: Der Marburger Bund hat Ende vergangenen Jahres nämlich die ersten arztspezifischen Tarifverträge unterzeichnet und tatsächlich für jüngere Ärzte bis zu 20 Prozent Gehaltssteigerungen herausgeholt. Dass man dafür künftig offiziell - zum Beispiel an den Unikliniken - statt 38,5 Stunden 42 Stunden arbeiten muss? Geschenkt! Die meisten arbeiten ohnehin unentgeltlich länger. Weitere positiven Seiten des neuen Arzt-Tarifvertrages: Künftig ist unmenschlichen 24-Stunden-Schichten ein Riegel vorgeschoben, die maximale Wochenarbeitszeit wurde begrenzt und Bereitschaftsdienste werden als Arbeitszeit gewertet - zumindest steht es so auf dem Papier der Tarifverträge ... Mehr dazu - und auch zu den negativen Seiten der Abschlüsse - in unserem Artikel „Neue Tarifordnung: Wer verdient wie viel?“ auf $\Rightarrow$ S. 24!

__ Ihr blaues Wunder erlebt haben einige der Pioniere, die bei der ersten „Zweiten Ärztlichen Prüfung“ nach neuer AO - vulgo „Hammerexamen“ - teilgenommen haben. Wie befürchtet, kamen zahlreiche Examenskandidaten unter die Räder: 70 von 716 Teilnehmern (9,8 Prozent) sind durchgefallen. Das sind mehr als doppelt so viele wie bei vergleichbaren früheren Prüfungen. Kein Wunder! Wer hat schon nach arbeitsreichen PJ-Tagen noch den Nerv, abends IMPP-Fragen zu kreuzen? Folgerichtig werden nach diesem verheerenden Ergebnis wieder Rufe lauter, das Hammerexamen in eine schriftliche Prüfung vor und eine mündliche Prüfung nach dem PJ aufzuspalten. Stimmen zu diesem Examen von Teilnehmern auf $\Rightarrow$ S. 22.

__ Zu guter Letzt noch zwei Tipps für Leute, die sich auch für Alternativen links und rechts von der klinischen Medizin interessieren: Schreiben Sie gerne? Werden Sie demnächst mit dem Studium fertig und möchten Sie als Mediziner in einem Verlag arbeiten? Dann sollten Sie sich unsere Stellenanzeige auf $\rightarrow$ S. 64 anschauen! Wir haben eine Volontariatsstelle zu besetzen. Bei uns lernen Sie alles, was Sie brauchen, wenn Sie später nicht nur als Arzt, sondern auch als Journalist arbeiten möchten. Wenn Sie dagegen damit liebäugeln, in die Industrie zu gehen, sollten Sie sich unseren Artikel „Projekte statt Patienten“ zu Gemüte führen $(\rightarrow$ S. 18). Wir schildern Ihnen beispielhaft einige Werdegänge von Ärzten, die in der freien Wirtschaft ihr Glück gefunden haben - vom Health-IT-Experten und dem Spezialist für Gesundheitskommunikation bis zur wundersamen Geschichte des Chirurgen John Harvey Kellogg - dem Erfinder der Cornflakes.

Ein wunderschönes Jahr 2007 wünscht Ihnen

Ihr
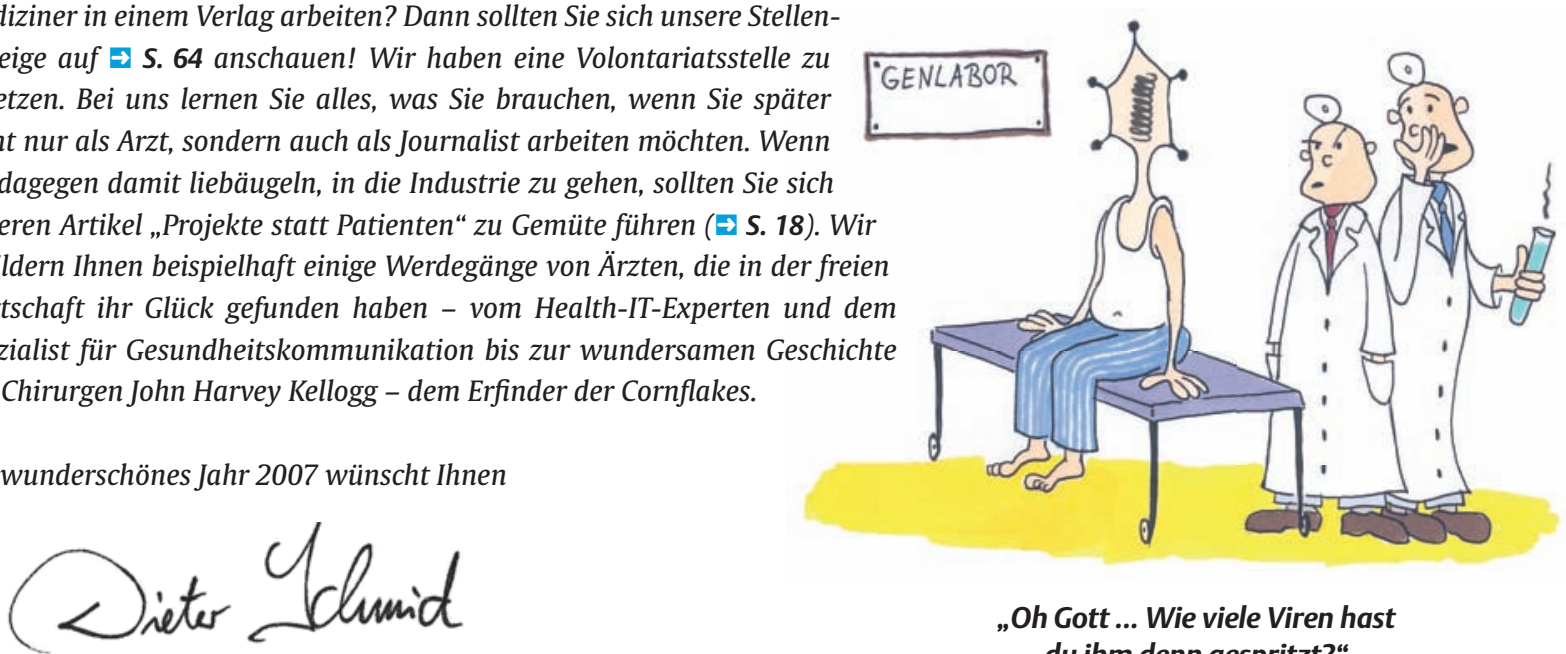

\section{„Oh Gott ... Wie viele Viren hast du ihm denn gespritzt?“}

